\title{
Weekly cisplatin may reverse liver dysfunction and jaundice caused by diffuse liver metastases of solid tumors
}

This article was published in the following Dove Press journal:

Hepatic Medicine: Evidence and Research

28 October 2009

Number of times this article has been viewed

\section{Gabrovska' \\ F Geurs' \\ S Ponette 2 \\ J Ponette ${ }^{2}$ \\ K Bulte ${ }^{2}$ \\ L Derveaux ${ }^{3}$ \\ I Kempeneers ${ }^{4}$ \\ 'Depts of Medical Oncology, ${ }^{2}$ Gastroenterology, ${ }^{3}$ Pneumology and ${ }^{4}$ Surgery, Regionaal Ziekenhuis Sint Maria, Halle, Belgium}

\begin{abstract}
Few data are available on patient management in jaundice caused by liver metastases of solid tumors (nonbreast and noncolon origin). We report the first patient series consecutively treated with cisplatin weekly in patients with severe jaundice and liver failure due to underlying metastatic neoplasms. In 4 out of 8 cases, liver function tests were reversed and jaundice disappeared, permitting subsequent standard chemotherapy. The other 4 patients died 3 to 5 weeks after admission, illustrating the extent and severity of the underlying neoplasm.
\end{abstract}

Keywords: liver failure, jaundice, metastases, chemotherapy, cisplatin

\section{Introduction}

Advances in chemotherapy and cytostatic drug pharmacology have made it possible for cancer patients with severe end organ failure to be treated with adapted drugs. Reports of patients with jaundice due to colon cancer, ${ }^{1}$ lymphoma, ${ }^{2}$ breast $^{3}$ and other tumor types ${ }^{4-9}$ are becoming more frequent. This knowledge has been drawn from a deeper insight into the pharmacology of drug clearance in cancer patients with liver dysfunction. ${ }^{10}$ Apart from case reports, ${ }^{11}$ however, there are no reports of series of patients presenting with severe jaundice, due to metastatic involvement of the liver, in which the treatment and outcome are summarized. We report here the first case series in this patient group, in which all patients were treated the same way with weekly cisplatin, until recovery of liver function, or death. Our study aimed to demonstrate that even in these patients, a relatively well tolerated drug like cisplatin may reverse the jaundice and liver failure, permitting further more classical chemotherapies.

\section{Methods}

This was a retrospective study conducted at Sint-Maria Hospital of Halle, Belgium. All medical records provided by the Hospital Tumor Registry were screened by one investigator to identify patients who met the study team's a priori selection criteria. These criteria included severe hyperbilirubinemia, due to unresectable metastatic cancer, and no prior cancer therapy (no prior surgery, or radiation, or chemotherapy).

The medical records of the patients identified in this screening process were then reviewed in depth: namely, date of diagnosis, dates of cisplatin treatment, subsequent laboratory changes and further treatment or death.

Patients were considered eligible if they had imaging studies (CT and ultrasound) with evidence of liver metastases of different types of carcinoma and exclusion of biliary tract obstruction. All included patients also had serum bilirubin levels higher

submit your manuscript | www.dovepress.con 
than $2.0 \mathrm{mg} / \mathrm{dL}$. Patients were required to have: WHO performance score 1 to 3 ; neutrophil count $>1500 \mathrm{~mm}^{3}$; platelet count $>100,000$; and normal serum creatinine at screening before starting chemotherapy. Eight patients were recruited, 4 men and 4 women.

Tumor responses were not assessed because of inconsistent patterns in radiographic testing from patient to patient and because of the greater value placed on survival.

Patients received $75 \mathrm{mg} / \mathrm{m}^{2}$ cisplatin on days 1,8 and 15 on a 4-week cycle, repeated on days 8, 22, 29 and 36, as described by van den Burg. ${ }^{12}$ Patients with small cell lung carcinoma received subsequent therapy with etoposide, cisplatin and cyclophosphamide; ${ }^{6}$ those with unknown primary had subsequent therapy with carboplatin and taxol weekly. ${ }^{13}$

Physical examination, vital signs assessment, body surface area calculation, biochemistry and hematology tests, and adverse-event assessment were performed prior to each dose of chemotherapy. Myeloid colony-stimulatory factors were not used because of the limited myelosupression of cisplatin.

\section{Results}

Patient characteristics are shown in Table 1. Liver tests at baseline and prior to each treatment cycle are shown in Table 2.

Four patients died after 2 or 3 cycles of treatment because of progressive cancer. The remaining 4 patients completed treatment with 4 to 6 cycles of cisplatin and received subsequent therapy adapted to the tumor type (Table 2). The most frequently reported adverse events were neurotoxicity, ototoxicity and anemia.

All patients initially showed a further rise of serum bilirubin with subsequent normalization of bilirubin after administration of second cycle of cisplatinum, as shown in Table 2. Alkaline phosphatase and alanine aminotransferase followed the same evolution as bilirubin.
Two patients remain alive at time of writing, more than 16 months and 4 months, respectively. Median overall survival was 127 days.

\section{Discussion}

This study assessed the efficacy of treatment with weekly cisplatin in liver failure due to liver metastasis of common solid tumors. Weekly cisplatin was proven to be efficacious in diverse tumor types such as NSCLC, ${ }^{14}$ head and neck cancer, ${ }^{15}$ and ovarian cancer. ${ }^{16}$ Its unique renal elimination permits administration in patients with severe jaundice and subsequent poor liver function. ${ }^{17,18}$ The results of this retrospective analysis suggest that 4 to 6 courses of weekly cisplatin rapidly lead to normalization in serum bilirubin and other liver tests, which permits subsequent chemotherapy with cytotoxics with hepatic metabolism such as etoposide, cyclophosphamide and taxanes. Four patients died after the first administration, mostly due to concomitant pulmonary disease and low WHO performance score at baseline. Other side effects were related mainly to platinum-induced toxicities like anemia and ototoxicity. There were no treatment delays due to myelosuppression. The most well known side effect of cisplatin, namely vomiting and nausea, was vigorously prevented by administration of granisetron, aprepitant and steroids. As noted in the initial publication, ${ }^{12}$ there were no cases of renal insufficiency due to the nephroprotective effect of hypertonic saline in which the cisplatin was dissolved. All 4 surviving patients had normal serum creatinine during cisplatin treatment and this did not change during later chemotherapies.

Unfortunately, it was not feasible to incorporate quality of life measures into this pilot study. Larger studies of this regimen in this patient group should include such measures in an attempt to assess the risk/benefit ratio for this palliative treatment.

Prior publications and case series as well as the current series underline the growing interest of oncologists in treating these patients whose prognosis is dismal without

Table I Patient characteristics

\begin{tabular}{|c|c|c|c|c|c|c|}
\hline Patient No & Age (years) & $\operatorname{Sex}(m / f)$ & Tumor type & Survival & Start date & Date of death \\
\hline I & 65 & $\mathrm{~m}$ & SCLC & 360 days & $3 / 1 / 2004$ & $4 / 9 / 2005$ \\
\hline 2 & 53 & $f$ & Papillar serous ovarian cancer & $350+$ days & $8 / 2 / 2008$ & Alive \\
\hline 3 & 84 & $\mathrm{~m}$ & SCLC & 3 days & I I/I8/2005 & ||$/ 2 \mid / 2005$ \\
\hline 4 & 69 & $\mathrm{~m}$ & SCLC & 210 days & $8 / 16 / 2003$ & $4 / 3 / 2004$ \\
\hline 5 & 80 & $f$ & ACUP with liver $M+$ & 38 days & $9 / 23 / 2005$ & $1 \mathrm{I} / 8 / 2005$ \\
\hline 6 & 57 & f & ACUP with liver $M+$ & 150 days & $3 / 23 / 2000$ & $8 / 1 / 2000$ \\
\hline 7 & 59 & $\mathrm{~m}$ & Undifferentiated lung carcinoma with liver mets & 20 days & $21 / 08 / 08$ & $9 / 9 / 2008$ \\
\hline 8 & 66 & f & Advanced cholangiocarcinoma & $110+$ days & $6 / 26 / 2009$ & Alive \\
\hline
\end{tabular}

Abbreviations: ACUP, adenocarcinoma of unknown primary; SCLC, small cell lung cancer; $M+$, metastases. 
Table 2 Evolution of biochemistry during consecutive cisplatin courses

\begin{tabular}{|c|c|c|c|c|c|c|c|c|}
\hline \multirow[t]{2}{*}{ Patient no } & \multirow[t]{2}{*}{ Test } & \multicolumn{7}{|c|}{ Before cisplatin cycle (number) } \\
\hline & & $\mathbf{I}$ & 2 & 3 & 4 & 5 & 6 & \\
\hline \multirow[t]{3}{*}{ I } & Bilirubin (mg/dL) & 4.2 & 5.01 & 4.81 & 1.98 & 0.98 & \multirow{3}{*}{\multicolumn{2}{|c|}{$\begin{array}{l}\text { further chemo + cisplatin, } \\
\text { etoposide and } \\
\text { cyclophosphamide }\end{array}$}} \\
\hline & AP (U/L) & 808 & 908 & 804 & 500 & 208 & & \\
\hline & $\gamma-\mathrm{GT}(\mathrm{U} / \mathrm{L})$ & 1474 & 1662 & 1540 & 873 & 236 & & \\
\hline \multirow[t]{3}{*}{2} & Bilirubin (mg/dL) & 3.66 & 10.92 & 2.83 & 1.32 & & \multicolumn{2}{|c|}{$\begin{array}{l}\text { further treatment with oral } \\
\text { etoposide }\end{array}$} \\
\hline & $\mathrm{AP}(\mathrm{U} / \mathrm{L})$ & 1546 & 1623 & 1021 & 315 & & & \\
\hline & $\gamma-\mathrm{GT}(\mathrm{U} / \mathrm{L})$ & 1986 & 1632 & 1020 & 256 & & & \\
\hline \multirow[t]{3}{*}{3} & Bilirubin (mg/dL) & 5.59 & 7.92 & death & & & & \\
\hline & $\mathrm{AP}(\mathrm{U} / \mathrm{L})$ & 449 & 445 & & & & & \\
\hline & $\gamma-\mathrm{GT}(\mathrm{U} / \mathrm{L})$ & 797 & 793 & & & & & \\
\hline \multirow[t]{3}{*}{4} & Bilirubin (mg/dL) & 5.6 & death & & & & & \\
\hline & AP (U/L) & 166 & & & & & & \\
\hline & $\gamma$-GT (U/L) & 182 & & & & & & \\
\hline \multirow[t]{3}{*}{5} & Bilirubin (mg/dL) & 0.85 & 2.21 & 0.45 & death & & & \\
\hline & $\mathrm{AP}(\mathrm{U} / \mathrm{L})$ & 483 & 452 & $|3|$ & & & & \\
\hline & $\gamma$-GT (U/L) & 776 & 989 & 207 & & & & \\
\hline \multirow[t]{3}{*}{6} & Bilirubin (mg/dL) & 2.49 & 7.2 & 1.52 & I.I & I & 0.91 & further treatment + \\
\hline & AP $(U / L)$ & 457 & 622 & 309 & 198 & 153 & 124 & cisplatin/paclitaxel \\
\hline & $\gamma-\mathrm{GT}(\mathrm{U} / \mathrm{L})$ & 272 & 444 & 202 & 149 & 113 & 82 & \\
\hline \multirow[t]{3}{*}{7} & Bilirubin (mg/dL) & 2.24 & 5 & 5.43 & death & & & \\
\hline & $\mathrm{AP}(\mathrm{U} / \mathrm{L})$ & 1386 & 1158 & 782 & & & & \\
\hline & $\gamma-\mathrm{GT}(\mathrm{U} / \mathrm{L})$ & 871 & 968 & 713 & & & & \\
\hline \multirow[t]{3}{*}{8} & Bilirubin (mg/dL) & 10.01 & 10.56 & 3.59 & 1.95 & $\mathrm{I} .4 \mathrm{I}$ & 0.93 & further treatment + \\
\hline & $\mathrm{AP}(\mathrm{U} / \mathrm{L})$ & 355 & 355 & 455 & 269 & 138 & 105 & cisplatin/gemcitabin \\
\hline & $\gamma-\mathrm{GT}(\mathrm{U} / \mathrm{L})$ & 682 & 648 & 1365 & 884 & 450 & 249 & \\
\hline
\end{tabular}

Abbreviations: AP, alkaline phosphatase; $\gamma-\mathrm{GT}$, gamma glutamyl transferase.

chemotherapy in all series. Our patient series is unique because it represents the first series of patients with fewer chemotherapy-sensitive tumor types than those mentioned above, who were all treated with the same cytostatic. The pharmacologically driven administration of a well known cytostatic, such as cisplatin, with its clinical efficacy even in severe jaundice, is paramount to success and prolonged survival in a substantial number of patients.

\section{Conclusion}

This is the first reported series of 8 patients treated with weekly cisplatin for diffuse metastases of solid tumors causing severe jaundice (not metastases caused by colon or breast cancer). Although there were a significant number of early deaths, in 4 of our 8 patients liver function recovered sufficiently to enable further standard chemotherapies. Because of the rarity of the presentation and the poor general state of these patients, this series may serve as a basis for further treatments and observations.

\section{Disclosures}

The authors declare no conflicts of interest.

\section{References}

1. Walia T, Quevedo JF, Hobday TJ, et al. Colorectal cancer patients with liver metastases and severe hyperbilirubinemia: A consecutive series that explores the benefits and risks of chemotherapy. Ther Clin Risk Manag. 2008;4:1-4.

2. Irene M, Ghobrial MD, Robert CW. Therapeutic options in patients with lymphoma and severe liver dysfunction. Mayo Clin Proc. 2004;79:169-175.

3. Sharma RA, Decatris MP, Santhanam S, et al. Reversibility of liver failure secondary to metastatic breast cancer by vinorelbine and cisplatin chemotherapy. Cancer Chemother Pharmacol. 2003;52:367-370.

4. Haider FS, Smith RE, Khan S, et al. Primary hepatic lymphoma presenting as fulminant hepatic failure with hyperferritinemia: a case report. J Med Case Reports. 2008;2:279.

5. Bhati CS, Bhatt AN, Starkey G, et al. Acute liver failure due to primary angiosarcoma: a case report and review of literature. World J Surg Oncol. 2008;6:104.

6. Kaira K, Takise A, Watanabe R, Mori M. Fulminant hepatic failure resulting from small-cell lung cancer and dramatic response of chemotherapy. World J Gastroenterol. 2006;12:2466-2468.

7. Planting AS, van der Burg M, de Boer-Dennert M, et al. Phase I/II study of a short course of weekly cisplatin in patients with advanced solid tumors. Br J Cancer. 1993;68:789-792. 
8. Alexopoulou A, Koskinas J, Deutsch M, et al. Acute liver failure as initial manifestation of hepatic infiltration by a solid tumor: report of 5 cases and review of the literature. Tumori. 2006;92:354-357.

9. Schetty S, Holt AP, Syn WK, et al. Hematological malignancies presenting with acute liver injury: a single-centre experience. $Q \mathrm{JMed}$. 2008;101:949-953.

10. Kathryn MF, Michael M. Part II: Liver function in oncology: towards safer chemotherapy use. Lancet Oncol. 2008;9:1181-1190.

11. Geurs F, Vandewaeter S, Ponette S, et al. Successful and well-tolerated second line therapy with cetuximab, irinotecan, and raltitrexed in progressive liver disease due to metastatic colon cancer. J Gastrointest Cancer. 2008;39:26-28.

12. van der Burg M, de Wit R, van Putten WLJ, et al. Weekly cisplatin and daily oral etoposide is highly effective in platinum pretreated ovarian cancer. Br J Cancer. 2002;86:19-25.

13. Huebnar G, Link M, Kahne $\mathrm{CH}$, et al. Paclitaxel and carboplatin vs gemcitabine and vinorelbine in patients with adeno- or undifferentiated carcinoma of unknown primary: a randomised prospectieve phase II trial. Br J Cancer. 2008;100:44-49.
14. Planting A, Kho S, van der Burg M, et al. A phase II study of weekly high-dose cisplatin combined with oral etoposide in advanced non-small-cell lung cancer. Cancer Chemother Pharmacol. 1997; 40:347-352.

15. Osoba D, Band PR, Goldine JH, Connors JM, et al. Efficacy of weekly cisplatin-based chemotherapy in recurrent and metastatic head and neck cancer. Ann Oncol. 1992;3:57-62.

16. Verborg WA, Campbell LR, Highley MS, et al. Weekly cisplatin with oral etoposide: a well-tolerated and highly effective regimen in relapsed ovarian cancer. Int J Gynecol Cancer. 2008;18:228-234.

17. Decatris MP, Sundar S, O'Byrne KJ. Platinum-based chemotherapy in metastatic breast cancer: the Leicester (UK) experience. Clin Oncol. 2005; 17:249-257.

18. Wilop S, Dada R, Galm O, et al. Cisplatin as a single agent chemotherapy in patients with liver dysfunction due to metastases. Onkologie. 2009;32:400-404.

\section{Dovepress}

\section{Publish your work in this journal}

Hepatic Medicine: Evidence and Research is an international, peerreviewed, open access journal covering all aspects of adult and pediatric hepatology in the clinic and laboratory including the following topics: Pathology, pathophysiology of hepatic disease; Investigation and treatment of hepatic disease; Pharmacology of drugs used for

the treatment of hepatic disease. Issues of patient safety and quality of care will also be considered. The manuscript management system is completely online and includes a very quick and fair peer-review system, which is all easy to use. Visit http://www.dovepress.com/ testimonials.php to read real quotes from published authors. 